\title{
IMMUNIZATION OF INFANTS WITH TRIPLE ANTIGEN
}

\author{
BY \\ G. V. FELDMAN \\ From the Department of Child Health, University of Manchester
}

(RECEIVED FOR PUBLICATION FEBRUARY 8, 1954)

The number of inoculations received by infants has reached formidable proportions. To minimize the number of injections required to produce full and effective immunization is one of the aims of all who are responsible for the prevention of disease in children. In recent years the efficacy of immunization procedures against diphtheria, tetanus and whooping cough has become apparent. The desirability of protection against diphtheria and whooping cough is accepted, but there are many who now believe that tetanus should be included, particularly in view of the fact that the deaths from tetanus in persons under 20 years of age in England and Wales number about 30 a year.

Our aim in this investigation was to demonstrate that infants of 3 months of age can be effectively immunized against diphtheria, tetanus and pertussis by the administration of a combined prophylactic. The literature contains favourable reports, particularly from the U.S.A., on the successful immunization of infants with a combined vaccine (di Sant'Agnese, 1947; Peterson and Christie, 1951). Earlier reports give evidence of successful protection conferred on young infants against pertussis and diphtheria, particularly when an adsorbed antigen has been used (Sako, Treuting, Witt and Nichamin, 1945; Bell, 1948; Kendrick, 1943).

It should be stated at the outset that in this trial no investigations were carried out on the antibody content of the infants' blood before immunization.

We used a combined antigen adsorbed on aluminium phosphate, in view of the reports (Sako et al., 1945; Sauer, 1946) that aluminium hydroxide adsorbed antigens give a better immunity response in infants than do plain suspensions of bacterial and fluid toxoids. The results of our subsequent investigations, in which we used unadsorbed prophylactics, will be reported.

The triple antigen used in the present trial contained $25 \mathrm{Lf}$. diphtheria toxoid, $2.5 \mathrm{Lf}$. tetanus toxoid and 20,000 million $H$. Pertussis organisms with the addition of $5 \mathrm{mg}$. of aluminium phosphate to the millilitre.
The infants were selected from those attending the clinic of the University Department of Child Health held at St. Mary's Hospital, Manchester. The only criteria for inclusion in the scheme were that the infant was healthy at the time of inoculation and that there was no family history of epilepsy or convulsions in childhood. To date 200 infants have been immunized.

The first injection $(0.5 \mathrm{ml}$.) was given at the age of 3 months, the second $(0.75 \mathrm{ml}$.) a month later and the third $(1.0 \mathrm{ml}$.) four to five months after the second. The reason for delaying the third injection was to use this as a 'booster' before the child became exposed to the extra risks of infection during the second year of life.

The antigen was given intramuscularly, deep into the upper and outer quadrant of the buttock, alternating the side used at successive injections to avoid superimposition. After drawing up the fluid in the syringe a fresh needle was used to ensure that none of the vaccine was injected into the subcutaneous tissue (which might be a possible cause of abscess formation). Similarly the leakage back along the track of the injection was minimized by inserting the needle obliquely.

Local reaction was common in the form of oedema and erythema, lasting sometimes for two or three days, but usually for no longer than 24 hours. In one case a local abscess formed in the subcutaneous tissue; the aspirated fluid was sterile on culture. One aspiration sufficed to effect a cure.

Some degree of constitutional upset was noted in many infants. Fretfulness for a few hours after the injection was the most common and in a few persisted for two days. Some vomited one or two feeds after their inoculation, but soon recovered and then fed satisfactorily. Drowsiness, for up to 12 hours after the injection, was occasionally reported. This had been noted much more frequently in a series of newborn infants immunized against pertussis (to be published) and did not seem to be a contraindication to further inoculation. Similarly, some mothers had remarked on the somnolence of 
their infants following diphtheria immunization alone. In only one case so far has it been thought necessary to discontinue the course of immunization and in this case the infant was stated to have vomited and been fretful for five days after the second injection.

An interesting complication, if such it be, remarked by one mother, was the occurrence of a harsh, barking cough beginning about four days after the injection and lasting for about a week. This had been noted by four or five mothers in the series (consisting of more than a thousand infants) inoculated with pertussis vaccine.

One month after the third injection blood was taken from 35 infants in order to assess the antibody content, i.e. diphtheria and tetanus antitoxins and $H$. pertussis agglutinins. Diphtheria antitoxins were titrated on guinea-pig skin and tetanus antitoxins in mice, according to methods recommended for testing prophylactics in the Therapeutic Substances Act. For the pertussis agglutinins standardized $H$. pertussis rabbit immune serum and antigen were used as controls. The serum was diluted 1 in 8 in saline, doubling over until a suitable end-point was attained. To one volume of the diluted serum in Dreyer's tubes one volume of $\boldsymbol{H}$. pertussis antigen at a concentration of $2,000 \times 10^{6}$ organisms per ml. was added. Test samples of sera were likewise diluted and $H$. pertussis antigen added to each dilution. The tubes containing the diluted serum plus the antigen were incubated overnight at a temperature of $37^{\circ} \mathrm{C}$.

Tables 1-4 give the results obtained.
TABLE 1

ANTIBODY TITRES

\begin{tabular}{|c|c|c|c|c|}
\hline No. & & $\begin{array}{c}\text { Pertussis } \\
\text { Agglutination } \\
\text { Titre }\end{array}$ & $\begin{array}{c}\text { Tetanus } \\
\text { Antitoxin } \\
\text { (units/ml.) }\end{array}$ & $\begin{array}{l}\text { Diphtheria } \\
\text { Antitoxin } \\
\text { (units/ml.) }\end{array}$ \\
\hline $\begin{array}{l}1 \\
2 \\
3 \\
4 \\
5 \\
6 \\
7 \\
8 \\
9 \\
10 \\
11 \\
12 \\
13 \\
14 \\
15 \\
16 \\
17 \\
18 \\
19 \\
20 \\
21 \\
22 \\
23 \\
24 \\
25 \\
26 \\
27 \\
28 \\
29 \\
30 \\
31 \\
32 \\
33 \\
34 \\
35\end{array}$ & \begin{tabular}{l|}
$\ldots$ \\
$\cdots$ \\
$\cdots$ \\
$\cdots$ \\
$\cdots$ \\
$\cdots$ \\
$\cdots$ \\
$\cdots$ \\
$\cdots$ \\
$\cdots$ \\
$\cdots$ \\
$\cdots$ \\
$\cdots$ \\
$\cdots$ \\
$\cdots$ \\
$\cdots$ \\
$\cdots$ \\
$\cdots$ \\
$\cdots$ \\
$\cdots$ \\
$\cdots$ \\
$\cdots$
\end{tabular} & $\begin{array}{l}<1 / 16 \\
<1 / 16 \\
1 / 128 \\
1 / 2,000 \\
1 / 3,000 \\
1 / 3,000 \\
1 / 1,500 \\
1 / 1,500 \\
1 / 256 \\
1 / 512 \\
1 / 1,000 \\
1 / 2,000 \\
1 / 4,000 \\
1 / 512 \\
1 / 2,000 \\
1 / 1,000 \\
1 / 1,500 \\
1 / 1,000 \\
1 / 512 \\
1 / 512 \\
1 / 2,048 \\
1 / 1,000 \\
1 / 1,500 \\
1 / 4,000 \\
1 / 2,500 \\
1 / 256 \\
1 / 2,048 \\
1 / 5,000 \\
1 / 2,000 \\
1 / 64 \\
1 / 3,072 \\
1 / 5,000 \\
1 / 1,000 \\
1 / 2,000 \\
1 / 1,000\end{array}$ & $\begin{array}{c}1 \cdot 87 \\
2 \cdot 37 \\
2 \cdot 37 \\
2 \cdot 37 \\
>2 \cdot 50 \\
5 \cdot 25 \\
\text { No serum } \\
2 \cdot 37 \\
2 \cdot 37 \\
7 \cdot 87 \\
>5 \cdot 50 \\
5 \cdot 22 \\
5 \cdot 50 \\
\text { No serum } \\
>8 \cdot 75 \\
>5 \cdot 50 \\
2 \cdot 47 \\
1 \cdot 37 \\
6 \cdot 38 \\
2 \cdot 62 \\
4 \cdot 12 \\
>8 \cdot 75 \\
21 \cdot 00 \\
>8 \cdot 75 \\
6 \cdot 38 \\
1 \cdot 3 \\
15 \cdot 75 \\
7 \cdot 13 \\
4 \cdot 38 \\
1 \cdot 92 \\
1 \cdot 31 \\
4 \cdot 38 \\
2 \cdot 62 \\
8 \cdot 75 \\
6 \cdot 12 \\
5\end{array}$ & $\begin{array}{r}1 \cdot 80 \\
3 \cdot 60 \\
0 \cdot 45 \\
4 \cdot 80 \\
4 \cdot 80 \\
11 \cdot 25 \\
17 \cdot 50 \\
8 \cdot 75 \\
12 \cdot 25 \\
6 \cdot 75 \\
8 \cdot 75 \\
3 \cdot 60 \\
4 \cdot 50 \\
\text { No serum } \\
7 \cdot 50 \\
4 \cdot 50 \\
6 \cdot 75 \\
7 \cdot 50 \\
7 \cdot 00 \\
6 \cdot 25 \\
8 \cdot 75 \\
12 \cdot 50 \\
15 \cdot 75 \\
15 \cdot 75 \\
7 \cdot 00 \\
1 \cdot 87 \\
8 \cdot 75 \\
7 \cdot 00 \\
5 \cdot 62 \\
2 \cdot 62 \\
5 \cdot 25 \\
3 \cdot 75 \\
11 \cdot 25 \\
7 \cdot 50 \\
5 \cdot 00 \\
\end{array}$ \\
\hline
\end{tabular}

\section{Discussion}

In addition to studying the development of antibodies in young infants following the injection of different antigens we also wished to ascertain if

TABLE 2

\begin{tabular}{c|c|c|c|c|c|c|}
\hline \multirow{2}{*}{ No. Tested } & \multicolumn{3}{|c}{ No. of Children with Diphtheria Antitoxin Level of } \\
\cline { 2 - 6 } 34 & $<0 \cdot 5$ & $0 \cdot 4-1 \cdot 0$ & $1 \cdot 0-2 \cdot 5$ & $2 \cdot 5-5 \cdot 0$ & $5 \cdot 0-10 \cdot 0$ & $10 \cdot 0-20 \cdot 0$ \\
\cline { 2 - 6 } & 0 & 1 & 2 & 9 & 15 & 7 \\
\hline
\end{tabular}

TABLE 3

\begin{tabular}{c|c|c|c|c|c|}
\hline No. Tested & \multicolumn{3}{|c|}{ No. of Children with Tetanus Antitoxin Level of } \\
\hline \multirow{2}{*}{33} & $<1 \cdot 0$ & $1 \cdot 0-5 \cdot 0$ & $5 \cdot 0-10 \cdot 0$ & 10 \\
\cline { 2 - 4 } & 0 & 17 & 14 & 2 \\
\hline
\end{tabular}

TABLE 4

\begin{tabular}{c|c|c|c|c|c|c|c|c|c|c|c|c|c|}
\hline \multirow{2}{*}{ No. Tested } & \multicolumn{8}{c|}{ No. of Children with Pertussis Agglutination Titre of } \\
\hline \multirow{2}{*}{35} & $<1 / 16$ & $1 / 16$ & $1 / 32$ & $1 / 64$ & $1 / 128$ & $1 / 256$ & $1 / 512$ & $1 / 1,000$ & $1 / 2,000$ & $1 / 4,000$ \\
\hline & 2 & 0 & 0 & 1 & 1 & 2 & 4 & 10 & 11 & 4 \\
\hline
\end{tabular}


there was any interference or competition between the antigens.

The results indicate a uniformly satisfactory response to tetanus and diphtheria antigens and to 33 out of 35 pertussis inoculations, so that if one accepts the experimental work of Barr and LlewellynJones (1953), suggesting that, unless optimal proportions of diphtheria toxoid and tetanus toxoid are present in a vaccine, antagonism is likely to occur, the proportion of the constituents in this vaccine may be considered good.

The protective level of tetanus antitoxin in man is uncertain, but figures commonly expressed are between 0.01 and 0.1 unit of antitoxin per $\mathrm{ml}$. (Bigler, 1951). In the present series the antitoxin level in all the infants a month after the third injection was far greater.

Vahlquist (1949) states that passively transmitted diphtheria antitoxin levels exceeding $0 \cdot 1$ unit per $\mathrm{ml}$. interfere with active immunization and that levels below 0.02 unit per ml. do not. Barr (1950), by calculating the rate of loss of maternally acquired antibody and assessing the cord blood levels in infants estimated that, in two districts surveyed, $80 \%$ of the child population could be successfully immunized at 3 months of age. The level of antitoxin required to produce immunity is considered to be 0.03 unit per $\mathrm{ml}$. All the infants immunized in the series reported in this paper achieved far higher titres, but it is possible that the lower titre in some children may be due to the presence of antitoxin from the maternal circulation before the injection of the vaccine. It seems, therefore, that at this age babies can be successfully immunized against diphtheria, despite the fact that a small proportion of them may still have a certain amount of maternal antibody. From other trials evidence is forthcoming that children with a high titre of maternal antitoxin immunized even at an earlier age than 3 months will acquire a basic immunity to diphtheria, although the level of actively produced antitoxin in their blood may be low. If such children receive booster doses at a later age they will respond with an antitoxin outflow in the same way as will children with no, or only traces of, maternal antitoxin at the time of primary immunization. The antitoxin assessment gives, therefore, a quantitative but not a qualitative evaluation of acquired immunity. The figures in Table 1 would also appear to confirm the view that in a properly balanced mixture of antigens there is no danger of these antigens interfering with each other's action.

Although it cannot be stated that a certain level of agglutinins will ensure partial or complete protection against pertussis, it may nevertheless be regarded as an indication of an immunological response to a bacterial antigen. From field trials conducted in this country it is hoped to learn how far agglutinin levels produced as a response to a vaccine can be related to the degree of protection against pertussis. In our series most children developed an agglutinin titre of 1 in 64 or above which figure we believe to be of certain significance.

In this series of tests we have injected graded doses of the antigen $(0.5,0.75$ and $1 \mathrm{ml}$.) and the children have responded well. It is known, however (Sako et al., 1945), that young babies respond better to adsorbed antigens than to plain fluid antigens. It should therefore be borne in mind, when immunizing young babies, that the doses, particularly the first dose used in the primary stimulus, should be greater when fluid toxoids or plain vaccines are used than when adsorbed antigens are given, in view of the findings of Barr and Glenny (1945), who have shown the importance of the size of the first dose in achieving a satisfactory basic immunity.

From Table 1 it can be seen that some children produced higher titres against pertussis than against diphtheria or tetanus and vice versa. This would indicate that the individual antigenic response to the three components is an independent phenomenon and may vary with each child.

It was not possible, in view of the infrequency of severe reactions, to deduce any relationship between the severity of reaction and the antibody titre.

\section{Summary}

In a series of more than 200 infants, antibody response to all three constituents of a triple antigen was satisfactory in those tested.

The reactions were no more severe than those following single antigens.

Because the addition of tetanus does not interfere with the production of diphtheria and pertussis antibodies its inclusion is a useful addition to the routine protection of children.

Thanks are due to Professor Wilfrid Gaisford for his constant encouragement and advice, to Dr. D. G. Evans for his advice, for his cooperation, to Dr. J. Ungar, of Glaxo Laboratories, Ltd., and to that Company, which supplied the triple antigen used in this trial.

\section{REFERENCES}

Barr, M. (1950). Lancet, 1, 1110.

and Glenny, A. T. (1945). J. Hyg., Lond., 44, 135.

and Llewellyn-Jones, M. (1953). Brit. J. exp. Path., 34, 12

Bell, J. A. (1948). J. Amer. med. Ass., 137, 1276.

Bigler, J. A. (1951). Amer. J. Dis. Child., 81, 226.

Kendrick, P. L. (1943). Amer. J. Hyg., 38, 193.

Kendrick, P. L. (1943). Amer. J. Hyg., 38, 193.

Peterson, J. C. and Christie, A. (1951). Amer. J. Dis. Child., 81, 483.
Sako, W., Treuting, W. L., Witt, D. B. and Nichamin, S. J. (1945). J. Amer. med. Ass., 127, 379.

Sant'Agnese, P. A. di (1947). J. Pediat., 31, 251.

Sauer, L. W. (1946). Med. clin. N. Amer., 30, 45.

Vahlquist, B. (1949). Lancet, 1, 16. 